\title{
A Spectrum of Employee Reactions to the Adoption of Organizational Changes in the AEC Industry
}

\author{
Omar N. Maali, M.S., PMP, Amirali S. \\ Shalwani, M.S., and Brian C. Lines, Ph.D. \\ University of Kansas \\ Lawrence, Kansas
}

\author{
Kenneth T. Sullivan, Ph.D., MBA \\ Arizona State University \\ Tempe, Arizona
}

\author{
Anthony Perrenoud, PhD \\ Boise State University \\ Boise, Idaho
}

\begin{abstract}
The architecture, engineering, and construction industry is introduced to a lot of innovations in various areas such as technology, management process, and business structure. The industry is rapidly adopting changes to cope with the current market. Many change initiatives fail to achieve their intended outcomes due to multiple barriers such as employee resistance to change. The objective of the study was to investigate the relationship between various employee reactions to change initiative and successful adoption of that change, using a continuum of eight observable employee reactions. The study collected a data set of 447 cases of organization-wide changes from AEC firms across North America. The results showed that a more favorable employee reaction to change is positively correlated with successful adoption of change. Further analysis considered each reaction separately to find which behavioral responses are most associated with successful change adoption. A key finding was that reactions of reluctant compliance, passive avoidance, and lack of participation were most strongly associated with negative change adoption. This leads to an interesting contribution for practitioners, because this finding suggests that organizations may need to be wary of these more subtle behavioral reactions than more overt opposition, argumentation, obstruction, and undermining actions.
\end{abstract}

Key Words: Employee Reactions, Successful Change Adoption, Resistance to Change, Organizational Change, Architectural, Engineering, and Construction (AEC)

\section{Introduction}

The architecture, engineering, and construction (AEC) industry is generally not considered as an industry that fosters changes and was accused of lagging behind other industries in adopting changes (Bygballe \& Ingemansson, 2014). However, in recent years organizations in the AEC industry are rapidly adopting new changes to keep competitiveness by delivering services more effectively and efficiently (Rahman, 2014). There are various types of changes the industry is adopting such as the adoption of new software (software systems for project management, building information modelling, 
and others) and hardware (remote sensors, mobile solutions, drones, and others). Another change type is the adoption of new project delivery methods (design-build, construction manager at risk, publicprivate-partnerships, and others) and business process improvements (knowledge management systems, quality management programs, alternative procurement methods, and others), in addition to the adoption of new organizational structures, such as mergers, acquisitions, hierarchical reorganizations, entering new markets, and others. These major types and sub-types of transformation were considered in the analysis along with several demographic characteristics. While many change adoptions fail it is essential for organizations to successfully adopted changes to achieve the benefits of that change and to cope with current market pressure to enhance productivity and reduce costs (Loosemore, 2014).

Adopting organizational changes is a resource-intensive and complicated task to do (Armenakis and Harris 2009). Many barriers stand in the way of change adoption (Ahn 2016; Rahman 2014). Employee resistance to change is one of the most cited barrier to change adoption (Bovey \& Hede, 2001b; Waldersee \& Griffiths, 1996; Maurer, 1997), while other researchers identified resistance to change as the primary reason for the productivity decline in the AEC industry for the past 50 years (Crew, 2017). Researchers have emphasized the importance of employee behaviors and their reactions to the change in achieving successful adoption of change (Holt et al. 2007; Jones et al.'s 2005). There is a need to understand the effect of observable employee reactions to change on the success of adopting changes in the AEC industry.

\section{Literature Review}

\section{Employees' Reactions to Change}

An interdisciplinary approach was conducted to understand the spectrum of employee reactions to organizational change efforts. Employee reaction to change includes a spectrum of reactions ranging from active or passive and from supportive to opposition. Many studies in the literature of organizational behaviors have categorized employee behaviors. For example, Lines (2005) categorized behaviors based on strength (from weak to strong) and attitude valence (ranging from negative to positive). Likewise, Bovey and Hede (2001b) categorized it as active or passive and overt or covert type of reactions. While Herscovitch and Meyer (2002) categorized employee reactions to change initiatives into favorable or unfavorable reactions.

\section{Successful Change Adoption and Employee Resistance to Change}

Achieving successful adoption of change is the final goal of every change initiative. Throughout the literature, this goal can be measured in multiple ways (Maali et al., 2020). Three factors were identified in the AEC literature to measure the success of change adoption (Aldossari et al., 2020; Lines and Varireddy, 2017). These factors are based on achieved benefits of the adoption, sustainability of the adopted change, and whether the change was adopted as intended. These three factors were used in this study.

Many studies in the organizational change literature have emphasized the important role employee reaction play as a barrier to change (Self \& Schraeder, 2009). Resistance to change implementation is one of the key barriers to successful change adoption (Bovey and Hede 2001b; Maurer 1997; Waldersee and Griffiths 1996). 
Similarly, in the context of the AEC industry, resistance to change may disrupt the change implementation process (Ahn et al. 2016; Chan et al. 2017; Zhou et al. 2019). Other researchers have identified resistance to change as a significant barrier to implementing change initiatives (Ozorhon et al., 2017). For example, resistance to change is a critical hindrance to implementing BIM (Liao \& Teo, 2018). Chan et al. (2017) identified that resistance to change is the most critical barrier to implementing green-building technologies. Additionally, Ozorhon et al. (2017) highlight the importance of overcoming employees' resistance to change to successfully adopt modern methods of construction and lean production.

\section{Methodology}

\section{Research Objectives}

The overall objective of this study was to understand the relationship between employee's reactions to change adoption effort and the adoption success of that change in the AEC industry. To achieve the study objectives, a survey questionnaire was used to collect 447 cases of organizational change. Each case represents a planned, intentional, and group-wide effort to implement a single change into the organization's long-term operations that occurred within an organization in the AEC industry.

\section{Survey Design, Distribution, and Collection}

The questionnaire was designed to be sent to AEC organizations that had recently experienced an organization-wide change in their process. The survey contains two sections. The first section focused on the participant demographics and the second part focused on research-related questions. In the second section of the survey, respondents were asked first to identify the change they were part of. Second, to rate the adoption success of that change using three factors on a 7-point Likert scale. Third, to identify the most prevalent employee reaction among involved employees. Respondents were asked to participate and complete the survey if they recently have been involved in a successful or unsuccessful organization-wide change in their process.

To ensure a broad selection of the AEC industry to be analyzed in the survey, email addresses were gathered from private, public, and professional groups and organizations in the AEC industry across the United States. A nationwide list of individuals and groups in the AEC industry was gathered. An online survey was used to gather collect the data, and a snowball approach was used where contacts on the mailing lists were asked to complete the survey and share it with other colleagues. Therefore, the exact number of sent-out surveys and response rate cannot be calculated (Muller and Turner, 2006).

The collected data were screened by removing incomplete responses or cases that are not related to organizational change adoption. The survey collected 447 complete responses of organizational change adoption cases from the AEC industry in North America. Each case represents an organizational effort to implement a single change into the organization's long-term operations in the AEC industry.

The collected data has the following descriptive results; (1) reference to the type of adopted change there are $38 \%$ of technological changes (software and hardware), $40 \%$ of Management process changes (project management and delivery), and $22 \%$ of changes in the business process (business improvement methods and structures). (2) reference to the organization sector, $34 \%$ are public 
organizations and $12 \%$ are private organizations. The balance $44 \%$ were missing responses. (3) for organization type, there are $48 \%$ owners/operators, $26 \%$ general and sub-contractors, $9 \%$ architecture and engineering firms, $10 \%$ other types of firms, and only $6 \%$ missing responses. (4) for respondent's job position, there are $17 \%$ senior executive, $32 \%$ regional managers, $27 \%$ project and crew members, $2 \%$ other positions, and $20 \%$ missing responses for the respondent job position.

\section{Definition of Variables}

\section{The spectrum of employee reactions}

Employee reaction variable was used as a measure of the most prevalent behavioral responses among the organization's staff who were involved in each organizational change initiative case. Employee reactions were measured on an 8-point Likert-like scale that represented a spectrum of active, passive, resistive, and supportive behaviors. The scale used in this study (shown in Table 1) was selected and categorized based on definitions of several studies from the organizational behavior literature (Bovey \& Hede, 2001a, 2001b; Emiliani \& Stec, 2005; Herscovitch and Meyers, 2002; Hultman, 2006). Similar scales have been used in the AEC literature (Vardireddy, 2017), yet most are limited to 5point Likert-like continuums (Lines et al., 2016); therefore, this study contributes a greater level of granularity regarding measures of employee reactions. For each change adoption case participants were asked to identify the most three dominant employee reactions to that change, average responses of the three selected reactions were used to create a blinded score for employee reaction to be used in the analysis for this study.

Table 1

The Spectrum of Employee Reactions

\begin{tabular}{|c|c|c|c|}
\hline $\begin{array}{l}\text { Reaction } \\
\text { Type }\end{array}$ & Scale & $\begin{array}{l}\text { The Spectrum of } \\
\text { Employee Reactions }\end{array}$ & $\begin{array}{l}\text { Definition of Observable Employee } \\
\text { Reactions }\end{array}$ \\
\hline \multirow{4}{*}{$\begin{array}{l}\text { Favorable } \\
\text { Reactions }\end{array}$} & 8 & Championing & $\begin{array}{l}\text { Initiating and embracing the change in the } \\
\text { organization }\end{array}$ \\
\hline & 7 & Actively Supporting & $\begin{array}{l}\text { Supporting the change within the } \\
\text { organization }\end{array}$ \\
\hline & 6 & Passively Supporting & Accepting the change \\
\hline & 5 & Reluctantly Complying & Just going with the change \\
\hline \multirow{4}{*}{$\begin{array}{l}\text { Unfavorable } \\
\text { Reactions }\end{array}$} & 4 & Passively Avoiding & Ignoring, withdrawing, avoiding the change \\
\hline & 3 & $\begin{array}{l}\text { Openly Not } \\
\text { Participating }\end{array}$ & Refraining, waiting, observing the change \\
\hline & 2 & Covertly Opposing & $\begin{array}{l}\text { Stalling, dismantling, undermining the } \\
\text { change }\end{array}$ \\
\hline & 1 & Overtly Opposing & Obstructing, opposing, arguing the change \\
\hline
\end{tabular}

\section{Successful change adoption}

To measure successful change adoption three factors were used including, whether the adopted change sustained for the long-term, whether the adopted change produced beneficial impacts, and 
whether the change adoption achieved its intended goals. These factors were measured on a 7- point Likert-type ordinal scale $(7=$ strongly agree, $6=$ agree, $5=$ somewhat agree, $4=$ neutral, $3=$ somewhat disagree, 2 = disagree, and $1=$ strongly disagree).

The three factors were used to obtain a single Change Adoption Construct (CAC), that provides an overall measurement of successful change adoption to be used in the analysis. CAC is a reliable and good indicator of successful change adoption in the AEC industry based on previous studies (Aldossari et al., 2020; Lines and Varireddy, 2017; Maali et al., 2020). Table 2 shows the description of CAC and the definitions of the three measurements of successful change adoption that were used in the survey. Respondents were asked to rate these three factors based on the change adoption in which they were involved in.

Table 2

Successful Change Adoption measured using Change Adoption Construct

\begin{tabular}{cl}
\hline $\begin{array}{c}\text { Measurements of Successful } \\
\text { Change Adoption }\end{array}$ & \multicolumn{1}{c}{ Definitions } \\
\hline Sustained long-term & $\begin{array}{l}\text { Sustained long-term Organizational change adoption was } \\
\text { sustained long-term within the company's operations (3 or } \\
\text { more years). } \\
\text { Produced beneficial impacts } \\
\text { Organizational change adoption resulted in a positive or } \\
\text { beneficial impact on the organization. }\end{array}$ \\
Achieved desired goals & $\begin{array}{l}\text { Organizational change adoption achieved the desired } \\
\text { outcomes within the organization's operations. }\end{array}$ \\
Change Adoption Construct & $\begin{array}{l}\text { Overall organizational change adoption was measured as the } \\
\text { linear composite of optimally weighted change adoption } \\
\text { variables. }\end{array}$ \\
\hline
\end{tabular}

\section{Research Analysis}

The objective of the study was to investigate the relationship between various employee reactions to change initiative and successful adoption of that change, using a continuum of eight observable employee reactions. To achieve research objectives, two bivariate analysis tests were performed on the collected data to (1) understand the overall correlation between employee reaction average score as the independent variable and successful change adoption using CAC as the dependent variable. (2) understand and categorize the correlation between each reaction of the eight employee reactions as the independent variables and successful change adoption, using $\mathrm{CAC}$ as the dependent variable.

First, Cronbach's alpha test and Principal Component Analysis (PCA) were used to obtain a single Change Adoption Construct (CAC) that provides an overall measurement of successful change adoption to be used in the bivariate analysis. Second, Spearman's rank-order correlation was used to establish bivariate relationships between variables (Employee reaction and CAC) and measure the strength and direction of these relationships. Spearman's rank-order correlation was utilized as it was a nonparametric test and a common analytical approach for use with ordinal data measures (McClure, 2005). All assumptions for spearman's rank correlation were met. 


\section{Results}

Cronbach's alpha value of 0.852 indicates a high level of internal consistency between the three measurements of successful change adoption (sustained long-term, produced beneficial impacts, achieved desired goals). PCA obtained one component for measuring successful change adoption (CAC).

The relationship between employee reaction average score and successful change adoption using CAC was analyzed using Spearman's rank correlation. The results of the analysis showed that a higher employee reaction score (which means more favorable and supportive reactions to change) had a significant moderate positive correlation $\left(\mathrm{r}_{\mathrm{s}}=0.33\right)$ with successful change adoption $(\mathrm{CAC})$, at a $\mathrm{p}$ value of 0.01 . The strength of associations was based on an established scale of small, moderate, and strong correlation for Spearman's rank correlation by Cohen (2013) for behavioral and social science studies.

Spearman rank correlation when conducted between each reaction of the eight employee reactions and successful change adoption using CAC also yielded some significant results. Table 3 below shows that all employee reactions had a significant correlation with successful change adoption, at a p-value of 0.01 except Passively Supporting which was not significant ( $P>0.05)$. Based on Cohen's (2013) established scale, one reaction Actively Supporting had a moderate positive correlation, while the remaining six reactions had an either small positive or negative correlation with successful change adoption (CAC).

Table 3

Spearman's Correlation between Employee Reactions and successful change adoption (CAC)

\begin{tabular}{cc}
\hline The spectrum of Employee Reactions & Spearman's rho $\left(\mathrm{r}_{\mathrm{s}}\right)$ \\
\hline Championing & $0.233^{*}$ \\
Actively Supporting & $0.301^{*}$ \\
Passively Supporting & -0.11 \\
Reluctantly Complying & $-0.170^{*}$ \\
Passively Avoiding & $-0.192^{*}$ \\
Openly Not Participating & $-0.172^{*}$ \\
Covertly Opposing & $-0.092^{*}$ \\
Overtly Opposing & $-0.123^{*}$ \\
\hline$*$ Correlation is significant at the 0.01 level (2-tailed) & \\
$\dagger$ Cohen $(2013)$ Established Statistical Correlation Scale for Behavioral and Social Science Studies \\
$0.1<\left|\mathrm{r}_{\mathrm{s}}\right|<0.3 \rightarrow$ Small Correlation & \\
$0.3<\left|\mathrm{r}_{\mathrm{s}}\right|<0.5 \rightarrow$ Moderate Correlation & \\
$\left|\mathrm{r}_{\mathrm{s}}\right|>0.5 \rightarrow$ Strong Correlation &
\end{tabular}

\section{Discussions}

Favorable and supportive employee reactions had a positive association with achieving successful organizational change adoption. This result aligns with previous studies from the literature of organizational change management (Bovey \& Hede, 2001b; Herscovitch and Meyer, 2002; Maurer, 
1997) and the AEC industry (Crew, 2017; Ozorhon et al., 2013; Vardireddy, 2017) where supportive employee reaction and less resistance are important to help achieve successful change adoption.

When analyzing the relationship between each reaction of the spectrum of employee reactions and successful change adoption four interesting results were presented. First, of the eight reactions only one reaction (Passively Supporting) did not have a significant association with successful change adoption even though it was considered as a favorable type of reaction. It means that passively supporting and agreeing on reactions do not affect achieving successful change adoption.

Second, for the seven significant reactions only one reaction (Actively Supporting) had a moderate association with successful change adoptions while other reactions had a low association with successful change adoption. It indicates that actively supporting and cooperating with the change effort is the key favorable reaction that contributes to the successful adoption of change. Third, the direction of correlation results (positive or negative) shows that the used spectrum of employee reactions is not categorized correctly. For the four favorable reactions from the used spectrum, only two had a positive correlation, the other two were neutral and unfavorable reactions to change (a positive correlation means that successfully adopting a change increases as favorable employee reactions increases, while a negative correlation means that successfully adopting a change decreases as favorable employee reactions decrease or unfavorable reactions increases). Forth, one of the most interesting findings is that the two extremes of employee reaction at the used spectrum were not the most significant reactions. Based on correlation results Actively supporting is the most favorable reaction instead of Championing the change, and Passively avoiding is the most unfavorable reaction instead of Openly opposing the change. It means that employees who ignore, withdraw, avoid, and covertly not participating in the change will negatively impact the successful adoption of that change more than employees with other unfavorable reactions such as openly opposing or openly not participating with the change effort. It is also important for practitioners to look for hidden types of resistive behaviors such as passively avoiding, rather than focusing only on open opposing types of behaviors.

\section{Conclusions and Limitations}

Change adoption is an essential part of any organization in the AEC industry to stay competitive and cope with the current market pressure. The adoption of change is a complicated demanding task, barriers and hindrances stand in the way of achieving successful change adoption for organizations. Employee resistance to change is one key barrier for successfully adopting a change in any organization, and it is the same for the AEC industry. To overcome this barrier and achieve a more successful change adoption, organizations should allocate resources and utilize practices to foster favorable reactions and highly focus on reducing subtle behavioral reactions such as passive avoidance and reluctant compliance, more than overt opposition, argumentation, obstruction, and undermining behaviors.

Research regarding the effect of employee reaction on successful organizational change adoption in the AC industry is limited. This study analyzed 447 cases of organizational change adoption in the AEC industry across North America, to understand the relationship of employee reactions on the successful adoption of changes and to help practitioners achieve better change adoptions. This study contributes to the body of knowledge by providing a greater level of granularity regarding measures of employee reactions to change adoption. Also, the study contributes to the industry by identifying which employee reactions have the greatest negative and positive impact on the successful adoption of change. Also, it might help practitioners to better allocate resources and efforts to eliminate unfavorable reactions and foster favorable reactions, which ultimately help the change adoption effort. 
Lastly, this study was limited to only eight employee reactions to change, and to initiatives in the AEC organizations in North America.

\section{References}

Ahn, Y. H., Kwak, Y. H., and Suk, S. J. (2016). "Contractor's Transformation Strategies for Adopting Building Information Modeling." Journal of Management in Engineering, 32(1): 05015005.

Aldossari, K. M., Lines, B. C., Smithwick, J. B., Hurtado, K. C., \& Sullivan, K. T. (2020). Best practices of organizational change for adopting alternative project delivery methods in the AEC industry. Engineering, Construction, and Architectural Management. (2020).

Armenakis, A., and Harris, S. (2009). "Reflections: Our journey in organizational change research and practice.” J. Change Manage., 9(2), 127-142.

Bovey, W. H., \& Hede, A. (2001a). Resistance to organizational change: The role of cognitive and affective processes. Leadership \& Organization Development Journal, 22 (8), 372-382.

Bovey, W. H., \& Hede, A. (2001b). Resistance to organizational change: The role of defense Bygballe, L. E., and Ingemansson, M. (2014). "The logic of innovation in construction.” Ind. Marketing Manage., 43(3), 512-524.

Chan, A. P. C., Darko, A., Ameyaw, E. E., and Owusu-Manu, D.-G. (2017). "Barriers Affecting the Adoption of Green Building Technologies." Journal of Management in Engineering, 33(3): 04016057.

Coetsee, L. (1999). "From resistance to commitment." Public Administration.

Cohen, J. (2013). Statistical power analysis for the behavioral sciences. Academic Press.

Crew, W. A. (2017). "Best Practices Create Innovation and Improved Competitiveness." Journal of Construction Engineering and Management, 143(9): 02517005.

Emiliani, M. L., and Stec, D. J. (2005). Leaders lost in transformation. Leadership \& Organization Development Journal, 26 (5), 370-387.

Herscovitch, L., and Meyer, J. P. (2002). "Commitment to organizational change: Extension of a three-component model." Journal of Applied Psychology, 87(3): 474-487.

Holt, D., Armenakis, A., Field, H., and Harris, S. (2007). "Readiness for organizational change: The systematic development of a scale.” J. Appl. Behav. Sci., 43(2), 232-255.

Hultman, K. E. (2006). Values-driven change: Strategies and tools for long-term success, iUniverse, Lincoln, NE.Q., 23(2), 204-222.

Jones, R. A., Jimmieson, N. L., and Griffiths, A. (2005). "The impact of organizational culture and reshaping capabilities on change implementation success: The mediating role of readiness for change.” J. Manage. Stud., 42(2), 361-386. 
Liao, L., and Teo, E. A. L. (2018). "Organizational Change Perspective on People Management in BIM Implementation in Building Projects." Journal of Management in Engineering, 34(3): 04018008.

Lines, B. C., \& Reddy Vardireddy, P. K. (2017). Drivers of Organizational Change within the AEC Industry: Linking Change Management Practices with Successful Change Adoption. Journal of Management in Engineering, 33 (6), 04017031.

Lines, B. C., Sullivan, K. T., \& Wiezel, A. (2016). Support for organizational change: Changereadiness outcomes among AEC project teams. Journal of Construction Engineering and Management, 142 (2), 04015062.

Lines, R. (2005). "The Structure and Function of Attitudes Toward Organizational Change." Human Resource Development Review, 4(1): 8-32.

Loosemore, M. (2014). Improving construction productivity: a subcontractor's perspective. Engineering, Construction, and Architectural Management, 21 (3), 245-260.

Maali, O., Lines, B., Smithwick, J., Hurtado, K., \& Sullivan, K. (2020). Change management practices for adopting new technologies in the design and construction industry. Journal of Information Technology in Construction, 25, 325-341.

Maurer, R. (1997). "Transforming resistance." HR Focus, 74(10), 9-10.

McClure, P. (2005). Correlation statistics: Review of the basics and some common pitfalls. Journal of Hand Therapy, 18 (3), 378-380.

mechanisms. Journal of Managerial Psychology, 16(7), 534-548.

Muller, R., \& Turner, J. R. (2006). Matching the project manager's leadership style to project type. International Journal of Project Management, 25 (1),21-32.

Ozorhon, B., and Karahan, U. (2017). "Critical Success Factors of Building Information Modeling Implementation." Journal of Management in Engineering, 33(3): 04016054.

Rahman, M. M. (2014). Barriers of implementing modern methods of construction. Journal of Management in Engineering, 30 (1), 69-77.

Self, D. R., \& Schraeder, M. (2009). Enhancing the success of organizational change. Leadership \& Organization Development Journal, 30 (2), 167- 182.

Vardireddy, P., 2017. Organizational Change Adoption Within the AEC Industry: Change Management Practices and Employee Reactions to Change. In B. Lines, M. Panethiere \& D. Tran (eds.): ProQuest Dissertations Publishing.

Waldersee, R., \& Griffiths, A. (1996). The Changing Face of Organizational Change. The University of New South Wales, Sydney.

Zhou, Y., Yang, Y., and Yang, J.-B. (2019). "Barriers to BIM implementation strategies in China." Engineering, Construction, and Architectural Management, 26(3): 554-574. 